\title{
The effect of mold temperature on chemical foaming of injection molded recycled polyethylene-terephthalate
}

\author{
Ferenc Ronkay ${ }^{\mathrm{a}, *}$, Bela Molnar ${ }^{\mathrm{a}}$, Gabor Dogossy ${ }^{\mathrm{b}}$ \\ ${ }^{1}$ Department of Polymer Engineering, Budapest University of Technology and Economics, H- \\ 1111 Budapest, Mủegyetem rkp. 3, Hungary \\ ${ }^{2}$ Department of Materials Science and Technology, Széchenyi István University, H-9026 \\ Györ, Egyetem tér 1, Hungary \\ * (corresponding author): ronkay@pt.bme.hu
}

\begin{abstract}
Foam injection molded samples were produced from recycled polyethylene-terephthalate using endothermic and exothermic foaming agents at different mold temperatures. The foam structure was analyzed by computer tomography and optical microscopy. The morphological properties of samples were analyzed by differential scanning calorimetry, using the three-phase model. Viscosities of the melts were changed during processing by endothermic and exothermic foaming agents, and as a result different foam structures were formed. Relationships between mold temperature and porosity were found. Morphologies of the samples made with different foaming agents were different, also due to the different cooling rates caused by the endothermic and exothermic foaming reactions.
\end{abstract}

\section{Keywords}

chemical foaming; recycled PET; injection molding; morphology;

\section{Introduction}

Since the appearance of polyethylene-terephthalate (PET) in 1970, it is the primary packaging material of beverage bottles. Its usage is expected to exceed $19 \mathrm{Mt}$ in the next few years [1] due to its excellent optical properties, gas-barrier ability, good impact resistance and low density. The life cycle of bottles is very short, and in practice the whole amount becomes waste within one year. The main application field of waste PET as secondary material is textile industry (fibers), but the bottle-to-bottle, sheet and strap production show an increasing tendency [2,3]. Different blends of recycled PET (RPET), such as PET/HDPE [4], PET/PP [5], and their composites [6] are popular research topics due to different polymers found in the waste. RPET application possibilities are also researched in the construction industry as additives in asphalt, in concrete, and in mortar [7, 8]. Usage as raw material of injection molded products can become a significant application field because of the good mechanical properties, but there are still a lot of phenomena to be interpreted [9].

The main problem during processing recycled PET is degradation, which limits the application of recycled PET as secondary material. The material can be subject to serious degradation in recycling processes due to heat, shearing and its moisture content. Paci and La Mantia [10] investigated the effect of moisture content and PVC content of raw material on degradation of PET, and they revealed a significant effect on processing parameters (torque of mixing bowl) and intrinsic viscosity (IV). Besides the effect on processability, degradation has a significant effect on the morphological and mechanical properties, as well. Badia et al. [11] investigated the mechanical properties of PET after multiple processing steps (from 1 to 5), and they 
observed decreasing impact strength, tensile modulus and stress as a function of reprocessing steps. Their results showed a significant loss in mechanical properties after application of the first reprocessing step, thus found a sort of threshold for PET to be recovered by further mechanical recycling.

A novel, less-researched but significant field of PET recycling could be the production of foamed products with different techniques. Foaming of polymers have several advantages: density decrease, production of insulation materials (such as EPS foam), in case of thick-walled injection molded products the advantages of technology can be utilized (e.g. decrease of sink marks, production of thick-walled products). Foaming can be carried out using physical methods where high pressure gas or low melting point additive is added or in a chemical way where the decomposition of additive creates the foaming gas [12]. The most influential factor regarding foaming is the IV value of the base material. In the literature, IV value above 0.9 is recommended since the viscosity of the material in melt state is one of the most influential factors during the foaming process [13]. In case of recycled material this value can be only reached if IV is increased - in most cases (solid state polycondensation - SSP, chain extenders) $[14,15]$. Production of foams with larger density is also possible from materials with low IV values. Several investigations have been carried out in the field of batch foaming of PET or RPET. This is a non-continuous foaming process, where the sample is put into a vessel and heated, and high pressure gas is used as a foaming agent [16-20]. Other, often used technology is extrusion, which is a continuous process. Xanthos et al [21] investigated physical foaming (with high pressure $\mathrm{CO}_{2}$ ) of recycled PET. They concluded that viscosity and melt strength of RPET is not particularly suitable for low density extrusion foaming, and they used chain extended RPET and original PET (with IV value of $0.95 \mathrm{dl} / \mathrm{g}$ ) for foaming process. Coccorullo et al [22] used chemical foaming agent to produce high density foams from RPET. They used chain extender because of the low IV of the RPET $(0.48 \mathrm{dl} / \mathrm{g})$ as well.

During foam injection molding of RPET cooling and shear have a significant effect on the molecular structure of PET, especially in thick-wall parts, because of the different cooling rate in the mold and in the middle of the part. The morphology evolved in the process and the foaming process can have significant effect on each other. Nowadays the three-phase morphological model is widely used for investigation of the microstructure of PET [11]. According to this model, PET has a crystalline (CRF), mobile amorphous (MAF) and rigid amorphous fraction (RAF). RAF is assigned to the crystalline-amorphous interface in basal lamellar planes, where the segments in the polymer chains are constrained on the crystalline side. MAF is the „traditional” amorphous fraction [23, 24]. Degradation process is mainly driven by the cleavage of MAF. The shortened chains rearrange in ordered phases, but crystallinity slightly changes: the ordered phases increase the RAF. This causes a bimodal melting behavior [11].

In this research thick-walled samples were injection molded from recycled PET using endothermic and exothermic foaming agents at different mold temperatures. Foam structure (density, cell size, cell position, porosity) evolved as a result of using exothermic and endothermic foaming agents were analyzed and compared using CT and optical microscopy. In order to understand the foaming process the rheological properties (IV, viscosity) of the base material and the gas and heat production of foaming agents during the process were investigated. Crystalline structure formed due to the application of different foaming agents was investigated using a three-phase morphological model. Relation was sought between mold temperature during sample production and the crystalline and foam structural properties.

\section{Materials and experimental}


PET regranulates with intrinsic viscosity (IV) $0.65 \pm 0.01 \mathrm{dl} / \mathrm{g}$ were supplied by Fe-Group Invest Zrt (Hungary). Two foaming agents were used from Tramaco: Tracel IM 3170 MS exothermic foaming agent with $120 \mathrm{ml} / \mathrm{g}$ gas expansion, and Tracel IM 7200 endothermic foaming agent with $50 \mathrm{ml} / \mathrm{g}$ gas expansion. Both were added to raw material in the ratio of 4 wt $\%$. PET regranulates were dried for $5 \mathrm{~h}$ at $160{ }^{\circ} \mathrm{C}$ in a hot air oven. Samples were injection molded with Arburg Allrounder Advance 370S 700-290 injection molding machine. Melt temperature was $280{ }^{\circ} \mathrm{C}$, injection rate was $40 \mathrm{~cm}^{3} / \mathrm{s}$, maximum injection pressure (specific) was 650 bar, packing pressure (specific) and time were 150 bar and $3 \mathrm{sec}$, respectively. Different mold temperatures were used, listed in Table 1. Manufacturing was not possible with mold temperature under $25^{\circ} \mathrm{C}$ using endothermic, and mold temperature above $45{ }^{\circ} \mathrm{C}$ using exothermic foaming agent. During injection molding the mold was opened to $0.1 \mathrm{~mm}$ for 20 seconds ("breathing mold technology"), which can help the foaming process, but this method resulted in a rougher surface of the moldings (because of the gas cells near the surface).

The injection molded samples had car door handle geometry (developed in previous research [25]), $8 \times 15 \mathrm{~mm}$ rounded cross-section, and are favorable for foam injection molding. The moldings were cut for 3 parts (Fig. 1), and the second (middle) part was investigated. In this part the foaming process was uniform because of the constant cross section.

The intrinsic viscosity of the base material was determined using a computer controlled PSL Rheotek automatic solution viscometer equipped with optical sensor. Phenol/tetrachloroethane mixture in the ratio of $60: 40 \%$ was applied as solvent, concentration was $0.5 \mathrm{~g} / \mathrm{dl}$, and examination temperature was $30^{\circ} \mathrm{C}$.

Viscosity curves were determined by Ceast SR20 capillary rheometer, at 260, 270, 280 and 290 ${ }^{\circ} \mathrm{C}$, in shear rate range $200-80001 / \mathrm{s}$.

Densities of raw material and foamed samples were determined by mass measurement with Ohaus Explorer analytical scale, calculated by equation (1):

$$
\rho_{s}=\rho_{e} m_{a} /\left(m_{a}-m_{e}\right),
$$

where $\rho_{s}\left[\mathrm{~g} / \mathrm{cm}^{3}\right]$ is the density of the sample, $\rho_{e}\left[\mathrm{~g} / \mathrm{cm}^{3}\right]$ is the density of ethanol, $m_{a}[\mathrm{~g}]$ is the measured mass of the sample in air, $m_{e}[g]$ is the measured mass of the sample in ethanol.

Temperature change of the melt caused by the endothermic or exothermic reaction of the foaming agents was determined by equation (2):

$$
\Delta T_{S}=Q_{F} /\left(c_{S} m_{S}\right)=\Delta h_{F A} m_{F} /\left(c_{S} m_{S}\right) \cong \Delta h_{F A} f_{F} / c_{P E T},
$$

where $\Delta T_{S}\left[{ }^{\circ} \mathrm{C}\right]$ is the change of the melt caused by the foaming agent, $Q_{F}[J]$ is the heat released during foaming reaction, $c_{S}[\mathrm{~J} /(\mathrm{gK})]$ is the heat capacity of the sample at the temperature of foaming reaction, $m_{S}[g]$ is the mass of the sample, $\Delta h_{F A}[\mathrm{~J} / g]$ is the enthalpy of the foaming agent released during foaming reaction, $m_{F}[g]$ is the mass of the foaming agent, $c_{P E T}[\mathrm{~J} /(\mathrm{gK})]$ is the heat capacity of PET at the temperature of the melt $\left(2.02 \mathrm{~J} /(\mathrm{gK})\right.$ at $\left.265^{\circ} \mathrm{C}\right)$ [26], $\mathrm{f}_{\mathrm{F}}[-]$ is the mass fraction of the foaming agent in the sample. The heat capacity of the sample has two components, the heat capacity of PET and foaming agent, but the latter was neglected since it is significantly low mass ratio compared to the PET.

The inner structure of parts was investigated with industrial X-ray CT equipment type YXLON Modular, resolution $0.027 \mathrm{~mm}$, tube voltage $200 \mathrm{kV}$, tube current $0.1 \mathrm{~mA}$. Detection was carried out using a flat panel, $700 \mathrm{~ms}$ integration time, without filter. 1440 projection images were taken for reconstruction. The obtained layer images were evaluated using the computer image processing algorithm developed at the Department of Materials Science and Technology, Széchenyi István University. The principle of examination is that porosity has much lower 
intensity in the scanned image than the material of the object, therefore if a cutting value is determined for the adequate intensity material and lack of material can be separated. The same cutting limit was applied in case of all images. Porosity was measured starting from the surface along the perimeter of the part. Skin thickness of the structure and the dimensions of the different layers were determined as a function of layer depth and porosity. Software VGStudio MAX 2.2 was used to determine the diameter of cells. Cell dimensions were also measured by Olympus BX51M optical microscope after the samples had been polished.

The morphological characteristics of RPET regranulates and injection molded specimens were determined with a DSC device type Setaram DSC131 EVO. One heating phase was applied during the measurement between 20 and $290{ }^{\circ} \mathrm{C}$, at $10^{\circ} \mathrm{C} / \mathrm{min}$ heating rate. The weight of examined samples was between 6 and $8 \mathrm{mg}$. The material structures were characterized with the three-phase model during the examinations. Crystalline fraction (CRF) was calculated by equation (3):

$$
C R F=\left(\left(\Delta h_{m}-\sum \Delta h_{c c}\right) / \Delta h_{m}^{0}\right) 100 \%,
$$

where $C R F$ is crystalline fraction in the sample [\%], $\Delta h_{m}$ is the specific enthalpy of melting $[\mathrm{J} / \mathrm{g}], \Delta h_{c c}$ is the specific enthalpy of cold crystallization $[\mathrm{J} / \mathrm{g}], \Delta h_{m}{ }^{0}$ is the specific melting enthalpy of $100 \%$ crystalline PET (140.1 J/g) [11]. The amount of mobile amorphous fraction (MAF) was determined based on the specific heat capacity change measured during glass transition by equation (4):

$$
M A F=\left(\Delta c_{p} / \Delta c_{p}^{0}\right) 100 \%,
$$

where $M A F$ is mobile amorphous fraction in the sample [\%], $\Delta c_{p}$ is the specific heat capacity change measured during glass transition $\left[\mathrm{J} /\left(\mathrm{g}^{\circ} \mathrm{C}\right)\right], \Delta c_{p}{ }^{0}$ is the specific heat capacity change of totally amorphous PET measured during glass transition $\left(0.405 \mathrm{~J} /\left(\mathrm{g}^{\circ} \mathrm{C}\right)\right)$ [11]. Rigid amorphous fraction (RAF) was determined by equation (5):

$$
R A F=100 \%-M A F-C R F,
$$

where $R A F$ is rigid amorphous fraction in the sample [\%], MAF is mobile amorphous fraction in the sample [\%], $C R F$ is crystalline fraction in the sample [\%].

\section{Results and discussion}

\subsection{Rheological properties of PET regranulates}

Figure 2 shows the viscosity curves of PET regranulate in the $260-290{ }^{\circ} \mathrm{C}$ temperature range. Viscosity measured at $290^{\circ} \mathrm{C}$ was 76 Pas in case of $200 \mathrm{l} / \mathrm{s}$ shear rate, and in case of 10 and 20 ${ }^{\circ} \mathrm{C}$ temperature increase viscosity increased to 102 and $136 \mathrm{l} / \mathrm{s}$, respectively. The viscosity of the base material changes significantly, by more than $10 \%$, even in case of a few ${ }^{\circ} \mathrm{C}$ temperature change, and that affects structure formed during foaming significantly.

\subsection{DSC curves, developed gas quantities, temperature change}

DSC curves of foaming agents are shown in Figure 3. In case of the decomposition of exothermic foaming agent (blue dashed line) $223 \mathrm{~J} / \mathrm{g}$ specific heat flow is generated, while in case of endothermic foaming agent (red continuous line) it is $444 \mathrm{~J} / \mathrm{g}$.

Foaming agent was added to the raw material in $4 \mathrm{~m} \%$, and that means $5{ }^{\circ} \mathrm{C}$ temperature increase (according to formula (2)) in case of exothermic foaming agent and $9{ }^{\circ} \mathrm{C}$ temperature decrease in case of endothermic foaming agent. It means that even $14{ }^{\circ} \mathrm{C}$ difference may arise between the melt temperatures when different foaming agents are applied, and hence significant 
differences can be experienced in viscosity that may result in different foam structures even under the same processing circumstances.

\subsection{Density and foam structure of samples}

The density of unfoamed samples was $1.36 \pm 0.0 \mathrm{~g} / \mathrm{cm}^{3}$ in case of all mold temperatures. If endothermic foaming agent was applied the average density of samples was $0.96 \pm 0.02 \mathrm{~g} / \mathrm{cm}^{3}$ and that means $29 \%$ decrease, while in case of exothermic foaming agent average density was $1.15 \pm 0.02 \mathrm{~g} / \mathrm{cm}^{3}$ and that is $14 \%$ decrease compared to unfoamed samples. The density of samples is strongly influenced by the foam structure formed during production. The foam structure formed at different mold temperatures is shown in Figure 4 in case of exothermic foaming agent and in Figure 5 in case of endothermic foaming agent.

The different foam structures and the porosity formed due to the two different foaming agents are revealed as a function of wall thickness in Figure 6. In case of exothermic foaming agent four different layers can be observed: a solid skin layer (1), a foamed skin layer with several but small size cells (2), a transition layer (3) and a foamed core layer with only a few but large size cells (4). Volumes of examined samples were $1093 \mathrm{~mm}^{3}\left(109.3 \mathrm{~mm}^{2}\right.$ cross section, $10 \mathrm{~mm}$ length) and that means the masses of the samples were $1.26 \mathrm{~g}$ in case of exothermic, and 1.05 $\mathrm{g}$ in case of endothermic samples. During the decomposition of exothermic foaming agents 120 $\mathrm{ml} / \mathrm{g}\left(120000 \mathrm{~mm}^{3} / \mathrm{g}\right)$ gas is formed and that means $6050 \mathrm{~mm}^{3}$ gas in case of the examined sample. Large cell size can be explained by the large pressure gas and the decrease in melt viscosity. Free energy necessary for cell formation increased in the specimen, surface tension decreased locally in the vicinity of the cells. Cells formed this way can easily grow with the help of diffusion [36]. Due to high pressure gas the mobility of cells increased in places where viscosity decreased to a great extent, therefore the cells diffused towards the surface of the specimen due to smaller external pressure (breath molding technology). Melt strength was larger in in the skin layer than in the core layer due to the more intensive cooling, hence cells that diffused from the core to the surface stopped in this place, therefore cell density in the skin layer was large. Average size of cells formed in this place remained small due to the high viscosity. The endothermic foaming agent develops $50 \mathrm{ml} / \mathrm{g}\left(50000 \mathrm{~mm}^{3} / \mathrm{g}\right)$ gas during decomposition, can exert smaller lifting force and distracts heat during the process that hinders cell growth and diffusion towards the surface due to the higher viscosity of the melt. Therefore in this case only 3 layers can be differentiated, a thicker solid skin layer (1), a transition layer (3) and a foamed skin layer with several but small size cells (4).

Figure 7 shows the characteristic porosities from the end of the samples $(0 \mathrm{~mm})$ till the middle of the samples $(4 \mathrm{~mm})$ of structures formed in case of exothermic and endothermic foaming agents. In case of the exothermic foaming agent 3 layers can be observed in the samples. Porosity curves reveal the size and proportions of each layer. The foamed skin layer can be found 1 to $1.5 \mathrm{~mm}$ from the edge of the sample, then from 2.5 to $2.9 \mathrm{~mm}$ comes the transition layer where porosity is only small extent (under 10\%). Then comes the middle foamed core part where porosity is nearly the same as in the skin part. In case of $25^{\circ} \mathrm{C}$ mold temperature foamed core layer is significantly larger than in case of the other 4 samples, and starts from nearly $1.8 \mathrm{~mm}$. In case of the endothermic foaming agent a solid skin layer can be experienced in case of all samples, and porosity increases continuously as the middle of the sample is approached.

Figure 8 shows the average porosity values of examined samples obtained with CT examinations. In case of higher mold temperature melt viscosity is smaller and that helps the spreading of gas cells in the material. In case of endothermic foaming agent melt temperature is lower and less gas is formed, therefore gas cells are smaller due to the lower pressure and are 
more dispersed in the sample and that results in higher porosity (and lower density as well). In case of exothermic foaming agent much more gas is formed and larger cells evolve due to the larger pressure and smaller melt viscosity, and cells move towards the surface and a part of gas may even leave through the surface since the mold is open. Consequently (also due to higher density), sample porosity decreases continuously as mold temperature increases.

Figure 9 shows the characteristic cell structure and cell size formed due to the two different foaming agents based on CT examinations. In case of exothermic foaming agent larger cells are formed in the sample compared to the application of endothermic foaming agent. However, when cell dimensions are evaluated it can be concluded that in case of endothermic samples the cell size cannot be determined since they are joined and cannot be separated. Therefore, the device senses these multi-cell units as one large volume, and cell dimensions cannot be evaluated in case of these samples.

Figure 10 shows the cell diameters determined from CT images and optical micrographs as a function of mold temperature. According to the CT results there is no significant difference between cell dimensions formed in case of the two foaming agents (exothermic samples: 280$350 \mu \mathrm{m}$, endothermic samples: 300-340 $\mu \mathrm{m}$ ), however this contradicts CT images (Figure 9). On the contrary, in case of optical microscopic examinations cell size is between 250 and 450 $\mu \mathrm{m}$ and that corresponds to the CT results, since the number of cells that were joined was small in that case. In case of endothermic samples cell diameters were between 80 and $160 \mu \mathrm{m}$ which is a much smaller result than those obtained from CT, however correspond to the structure on CT images (Figure 9) well.

\subsection{DSC examination of injection molded samples}

Crystalline structure of foamed specimens was measured with DSC. Examinations were carried out on the middle of the samples, on the foamed core part (Figure 6, layer 4), therefore impact of foaming on crystalline structure could be examined, and the effect of the two foaming agents could be compared.

Figure 11 reveals crystalline ratio as a function of mold temperature. When the core part of the samples was examined, CRF ratio of RPET that did not contain foaming agent was constant, around 29\%. CRF ratio of samples that contained endothermic foaming agent was also independent from mold temperature, however CFR was in average by 3-4\% lower than in case of samples without foaming agent. Due to the heat distracted during the decomposition of foaming agent the cooling of melt was more intensive, colder melt entered the mold, therefore crystallization was smaller extent. The CRF ratio of samples that contained exothermic foaming agent fluctuated around 34\%, which is larger by 3-5\% than that of samples without foaming agent. There might be two reasons for that: one is heat generated during the decomposition of foaming agent that increased the melt temperature, therefore larger CRF formed in those samples. The other is the structure formed during foaming (Figure 2) where a foamed skin layer can be observed at the edge of the sample. This functions as an insulation layer at the edge of the product and provides more time for the crystallization process as it decreases the cooling rate driven by the difference between the temperature of the melt and the mold.

RAF ratios in the samples are shown in Figure 12. Formation of RAF can be bound to the crystalline phases, and within that the surface of crystalline phases, meaning that as the specific surface of the crystalline phases increases, the ratio of rigid amorphous phase is supposed to increase to a certain extent. In RPET samples without foaming agent RAF is between 40 and $60 \%$, in endothermic samples between 32 and $36 \%$, while in case of exothermic samples fluctuates around $23-26 \%$, independent from mold temperature. The ratio among the different samples differs from what was experienced in case of crystalline ratio. A possible reason for 
that is that samples made of the original material have larger material volume (have no air bubbles), therefore although crystalline fraction is smaller, it contains a lot more but much smaller crystallites the surface-volume ratio of which is larger than that of crystallites formed in foamed samples.

Measurement of specific heat change at glass transition revealed the mobile amorphous fraction (MAF) of each sample. MAF values belonging to different mold temperatures are shown in Figure 13.

MAF ratio of both samples, with endothermic and with exothermic foaming agent was around $40 \%$. In case of samples without foaming agent this value fluctuated between 15 and $40 \%$ as a function of mold temperature. In case of foamed samples MAF is higher due to the smaller RAF than in case of the original base material.

\section{Conclusions}

In this research thick-walled products were injection molded from recycled PET using exothermic and endothermic chemical foaming agents. Foam structure and morphological properties of the prepared samples and the impact of mold temperature on the properties were examined.

Different foam structures were formed in the samples due to the two kinds of foaming agents. When endothermic foaming agent was applied, finer foam structure formed along the cross section with smaller cell size, while the density of products decreased by $29 \%$. In case of exothermic foaming agent a coarser structure with larger cell size formed, and the density decreased by $14 \%$. Although exothermic foaming agent develops more gas during its decomposition than the endothermic one, but due to the smaller melt viscosity and higher pressure gas cells approach the surface of the product and a part of the gas may even leave the product.

Porosity of samples showed strong relationship with mold temperature. As mold temperature increased the porosity of samples with endothermic foaming agent decreased, and that of samples with exothermic foaming agent increased. In case of endothermic foaming agent the gas cells formed are smaller and there is an increasing number of cells as the middle of the sample is approached, while in case of exothermic foaming agent a more porous layer can be found both in the edge and middle of the samples.

Crystalline structure of RPET and samples prepared with different foaming agents showed significant differences. The crystalline ratio of samples with foaming agent changed significantly compared to samples with no foaming agent. The crystalline ratio of samples with exothermic foaming agent increased, while that of samples with endothermic foaming agent decreased. The reason is the melt temperature difference and therefore the different cooling rate and time. RAF was smaller in case of foamed samples, while MAF was larger compared to that of the sample made of the original material. The reason is the different size and number of crystallites, and therefore their different surface-volume ratio.

Based on the results high density foams and thick-walled products can be produced if recycled PET is chemically foamed. Development and manufacture of foamed products may open new fields in PET recycling.

\section{Acknowledgement}

This research was realized in the frames of TÁMOP 4.2.4. A/1-11-1-2012-0001 "National Excellence Program - Elaborating and operating an inland student and researcher personal support system". The project was subsidized by the European Union and co-financed by the 
European Social Fund. The infrastructure of the research project was supported by the Hungarian Scientific Research Fund (OTKA K109224).

\section{References}

[1] H. Zhang, Z-G. Wen. The consumption and recycling collection system of PET bottles: A case study of Beijing, China. Waste Manage 2014;34:987.

[2] L. Shen, E. Worrell, M. K. Patel. Open-loop recycling: A LCA case study of PET bottle-to-fibre recycling. Resour Conserv Recy 2010;55:34.

[3] F. Welle. Twenty years of PET bottle to bottle recycling - An overview. Resour Conserv Recy 2011;55:865.

[4] K. Dobrovszky, F. Ronkay. Effects of SEBS-g-MA on rheology, morphology and mechanical properties of PET/HDPE blends. Int Polym Proc 2015;30:91.

[5] Y. Tao, Y. Pan, Z. Zhang, K. Mai. Non-isothermal crystallization, melting behavior and polymorphism of polypropylene in $\beta$-nucleated polypropylene/recycled poly(ethylene terephthalate) blends. Eur Polym J 2008;44:1165.

[6] R. M. Merijs, J. Zicans, R. Maksimovs, T. Ivanova, M. Kalnins, R. Berzina, G. Japins. Elasticity long-term behavior of recycled polyethylene terephthalate (rPET)/montmorillonite (MMT) composites. Compos Struct 2014;111:453.

[7] T. B. Moghaddam, M. Soltani, M. R. Karim. Stiffness modulus of Polyethylene Terephthalate modified asphalt mixture: A statistical analysis of the laboratory testing results. Mater Design 2015;68:88.

[8] Y. W. Choi, D. J. Moon, Y. J. Kim, M. Lachemi. Characteristic of mortar and concrete containing fine aggregate manufactured from recycled waste polyethylene terephthalate bottles. Constr Build Mater 2009;23:2829.

[9] N. Torres, J. J. Robin, B. Boutevin. Study of thermal and mechanical properties of virgin and recycled poly(ethylene terephthalate) before after injection molding. Eur Polym $\mathrm{J}$ 2000;36:2075.

[10] M. Paci, F. P. L. Mantia. Influence of small amounts of polyvinylchloride on the recycling of polyethylene terephthalate. Polym Degrad Stabil 1999;63:11.

[11] J. D. Badia, E. Strömberg, S. Karlsson, A. Ribes-Greus. The role of crystalline, mobile amorphous rigid amorphous fractions in the performance of recycled poly (ethylene terephthalate) (PET). Polym Degrad Stabil 2012;97:98.

[12] L. M. Matuana, O. Faruk, C. A. Diaz. Cell morphology of extrusion foamed poly(lactic acid) using endothermic chemical foaming agent. Bioresource Technol 2009;100:5947.

[13] J. Scheirs, T. E. Long, Modern Polyesters: Chemistry and Technology of Polyesters and Copolyesters, John Wiley and Sons, 2003.

[14] J. Zhao, H. Xiao, G. Qiu, Y. Zhang, N. Huang, Z. Tang. Solid-state polycondensation of poly(ethylene terephthalate) modified with isophthalic acid: kinetics and simulation. Polymer 2005;46:7309.

[15] P. Raffa, M-B. Coltelli, S. Savi, S. Bianchi, V. Castelvetro. Chain extension and branching of poly(ethylene terephthalate) (PET) with di- multifunctional epoxy or isocyanate additives: An experimental and modelling study. React Funct Polym 2012;72:50.

[16] L. Sorrentino, E. D. Maio, S. Iannace. Poly(ethylene terephthalate) Foams: Correlation Between the Polymer Properties and the Foaming Process. J Appl Polym Sci 2010;116:27. 
[17] A. M. Scamardella, U. Vietri, L. Sorrentino, M. Lavorgna, E. Amendola. Foam based on poly(ethylene terephthalate) nanocomposites with enhanced thermal stability. J Cell Plast 2012;48:557.

[18] H. Zhong, Z. Xi, T. Liu, L. Zhao. In-situ Polymerization-modification Process and Foaming of Poly(ethylene terephthalate). Chinese J Chem Eng 2013;21:1410.

[19] H. Guo, K. Nadella, V. Kumar. Effect of intrinsic viscosity on solid-state microcellular foaming of polyethylene-terephthalate. J Mater Res 2013;28:2374.

[20] S. Japon, Y. Letherrier, J-A. E. Manson. Recycling of Poly(Ethylene Terephthalate) Into Closed-Cell Foams. Polym Eng Sci 2000;40:1942.

[21] M. Xanthos, U. Yilmazer, S. K. Dey, J. Quintas. Melt Viscoelasticity of Polyethylene Terephthalate Resins for Low Density Extrusion Foaming. Polym Eng Sci 2000;40:554.

[22] I. Coccorullo, L. D. Maio, S. Montesano, L. Incarnato. Theoretical and experimental study of foaming process with chain extended recycled PET. eXPRESS Polym Lett 2009;3:84.

[23] R. Rastogi, W. P. Vellinga, S. Rastogi, C. Schick, H. E. H. Meijer. The Three-Phase Structure and Mechanical Properties of Poly(ethylene terephthalate). J Polym Sci Pol Phys 2004;42:2092.

[24] B. Wunderlich. Reversible crystallization and the rigid-amorphous phase in semicrystalline macromolecules. Prog Polym Sci 2003;28:383.

[25] B. Molnar. The Effect of Technological Parameters on the Foaming of Injection Molded, Recycled PET. Acta Techn Jaurinensis 2014;7:1.

[26] ATHAS databank, www.springermaterials.com (07.11.2015.) 


\begin{tabular}{ccc}
\hline RPET & $\begin{array}{c}\text { RPET + endothermic } \\
\text { foaming agent }\end{array}$ & $\begin{array}{c}\text { RPET + exothermic } \\
\text { foaming agent }\end{array}$ \\
\hline $6{ }^{\circ} \mathrm{C}$ & & $6{ }^{\circ} \mathrm{C}$ \\
$15{ }^{\circ} \mathrm{C}$ & $25{ }^{\circ} \mathrm{C}$ & $15{ }^{\circ} \mathrm{C}$ \\
$25{ }^{\circ} \mathrm{C}$ & $35{ }^{\circ} \mathrm{C}$ & $25{ }^{\circ} \mathrm{C}$ \\
$35{ }^{\circ} \mathrm{C}$ & $45{ }^{\circ} \mathrm{C}$ & $35{ }^{\circ} \mathrm{C}$ \\
$45{ }^{\circ} \mathrm{C}$ & $55{ }^{\circ} \mathrm{C}$ & $45{ }^{\circ} \mathrm{C}$ \\
$55{ }^{\circ} \mathrm{C}$ & $65{ }^{\circ} \mathrm{C}$ & \\
$65{ }^{\circ} \mathrm{C}$ & & \\
\hline
\end{tabular}

Table 1. Mold temperatures during injection molding 
Figure 1. Geometry of the product and the investigated part

Figure 2. Viscosity curves of the raw material at different temperatures

Figure 3. DSC curves of exothermic and endothermic foaming agents

Figure 4. Foam structures at different mold temperatures in case of exothermic foaming agent

Figure 5. Foam structures at different mold temperatures in case of endothermic foaming agent

Figure 6. Effect of exothermic and endothermic foaming agent on masked cuts from CT images in a $25^{\circ} \mathrm{C}$ mold, with notation of the different layers $(1$ - solid skin; 2 - foamed skin; 3 - transition; 4 - foamed core)

Figure 7. Characteristic porosities from the end of the samples $(0 \mathrm{~mm})$ till the middle of the samples $(4 \mathrm{~mm})$ formed in case of exothermic (on the left) and endothermic (on the right) foaming agents

Figure 8. Porosity formed due to exothermic and endothermic foaming agents as a function of mold temperature

Figure 9. Cell size based on CT images in case of exothermic and endothermic foaming agents

Figure 10. Average cell diameter as a function mold temperature based on CT images (left) and optical micrographs (right)

Figure 11. Crystalline ratio of samples made of original and foamed material as a function of mold temperature

Figure 12. Rigid amorphous fraction of samples made of original and foamed material as a function of mold temperature

Figure 13. Mobile amorphous fraction of samples made of original and foamed material as a function of mold temperature 


$$
\text { 学 }
$$




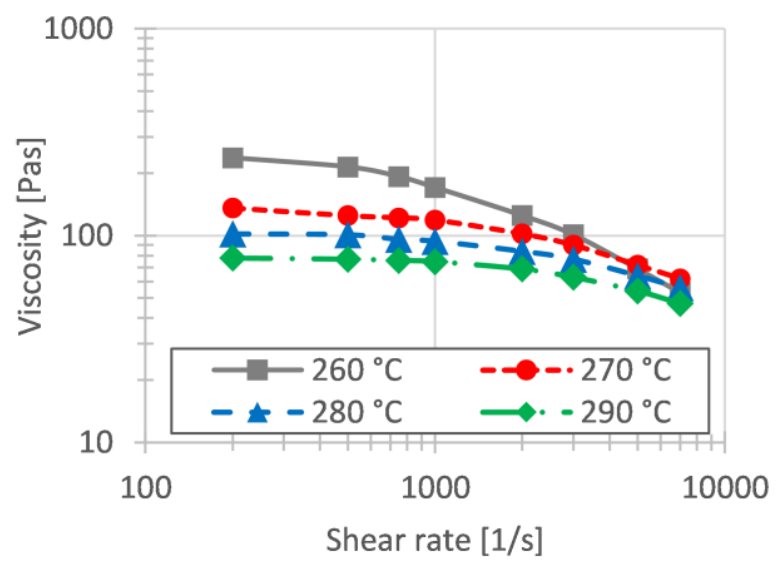




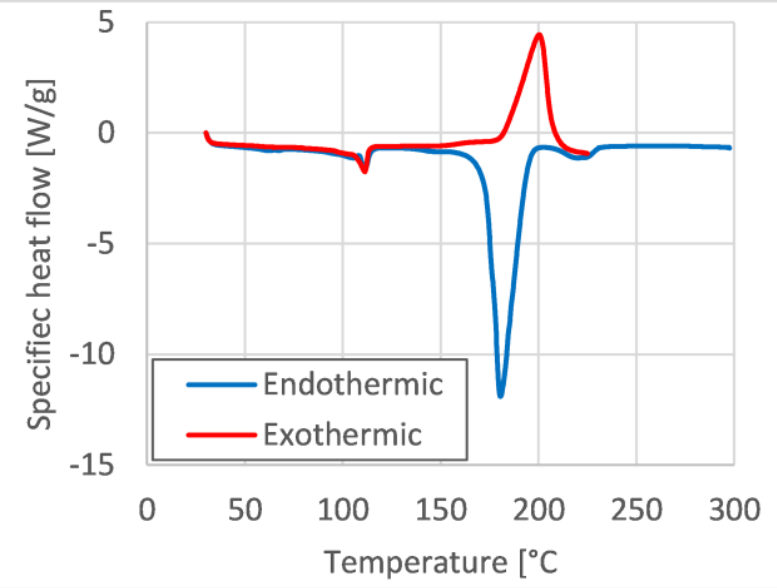




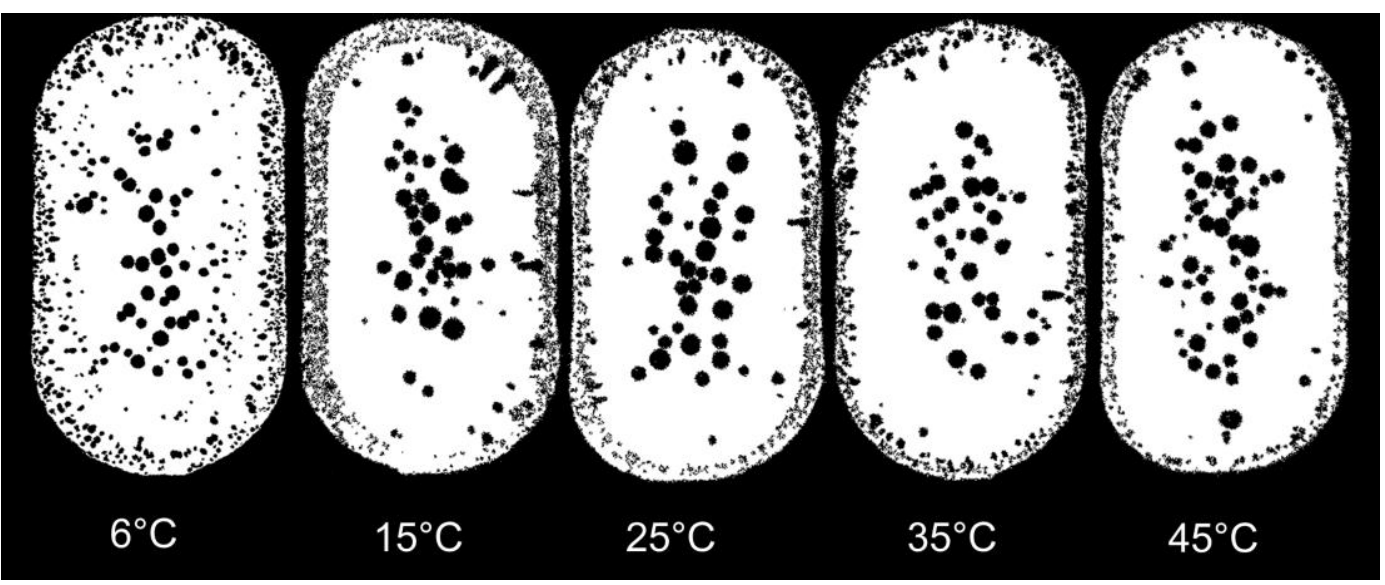




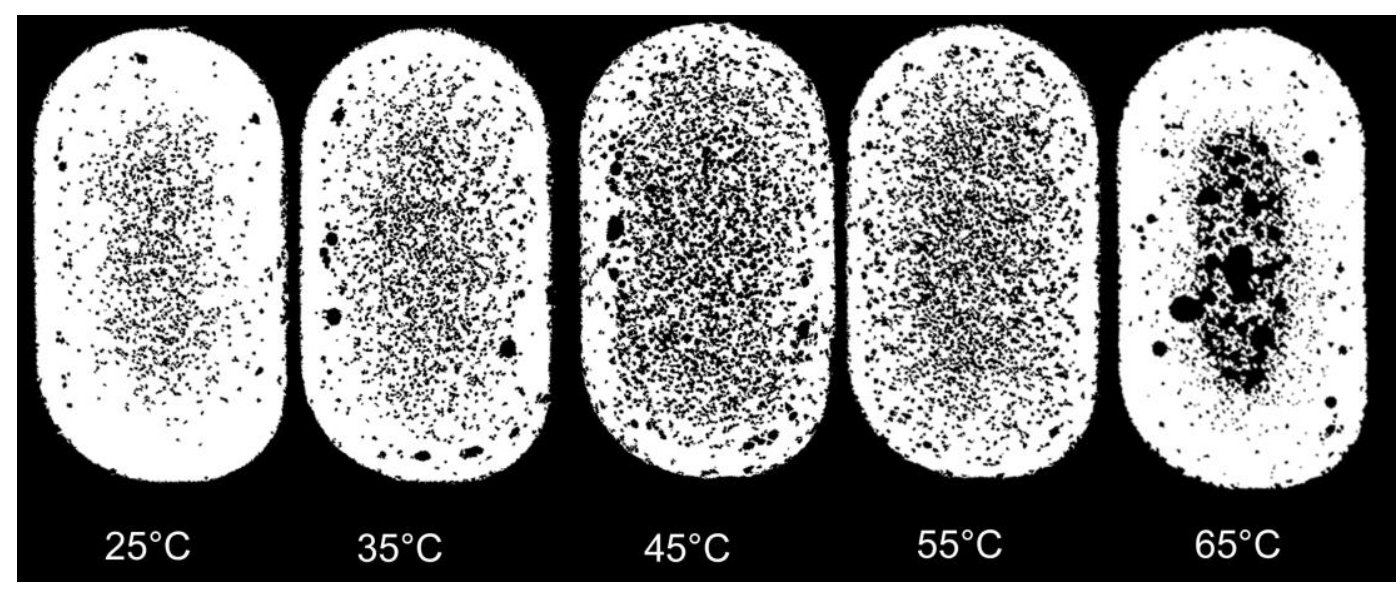




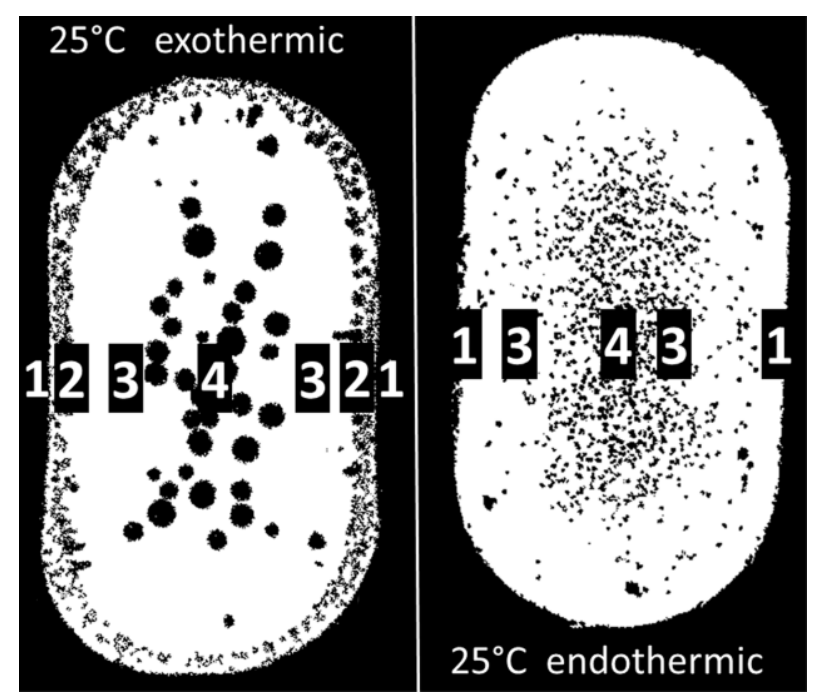



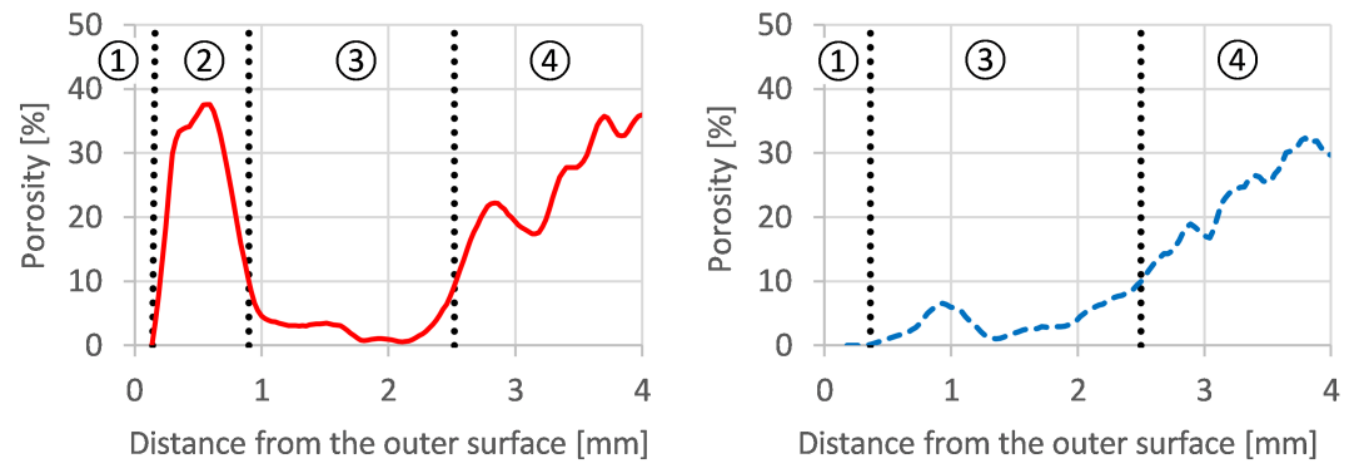


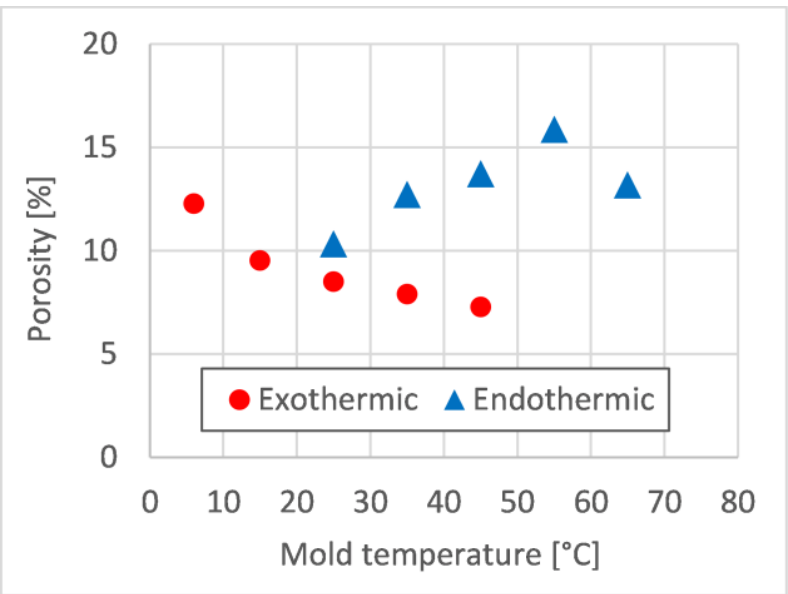




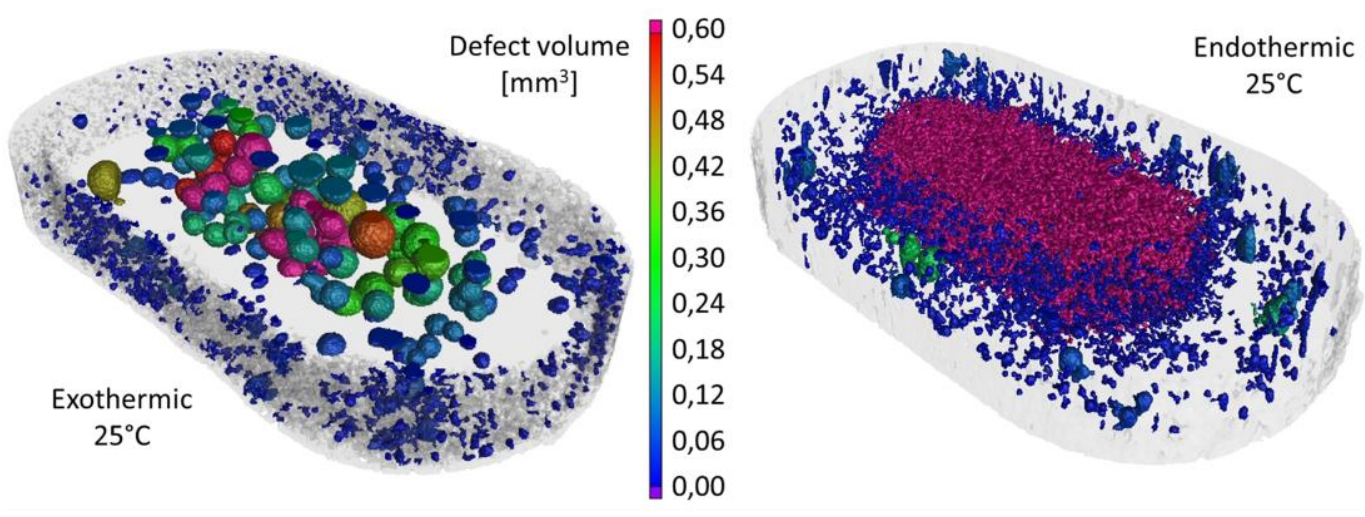



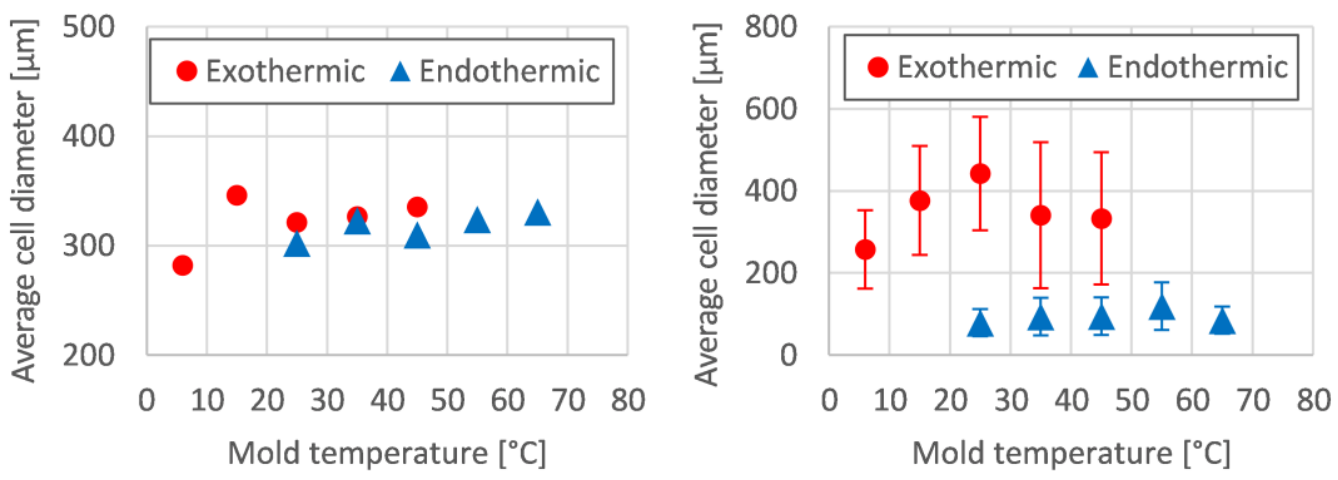


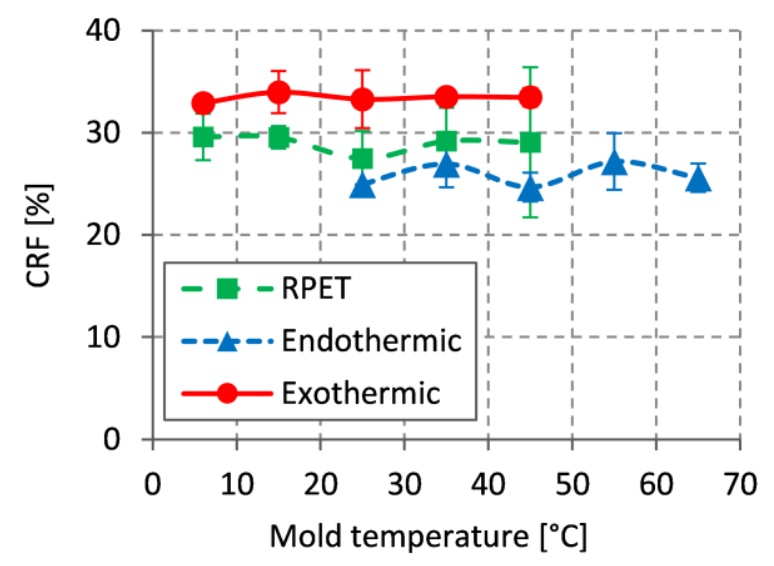




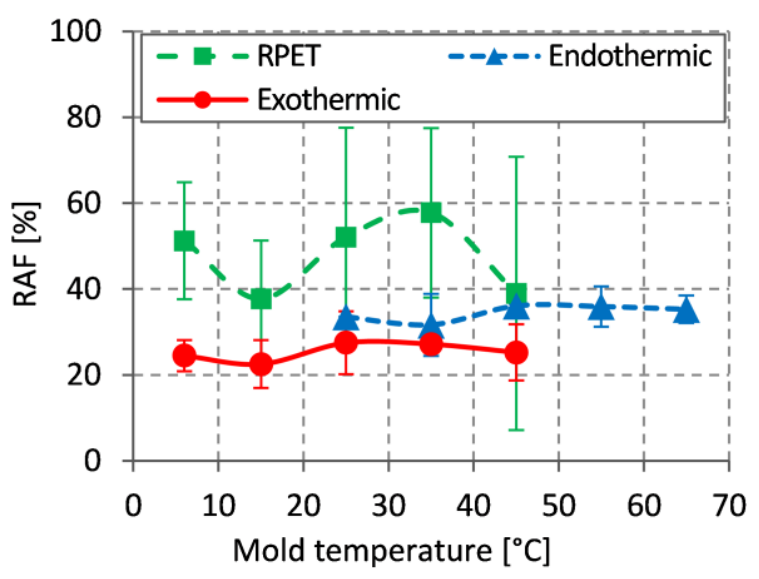




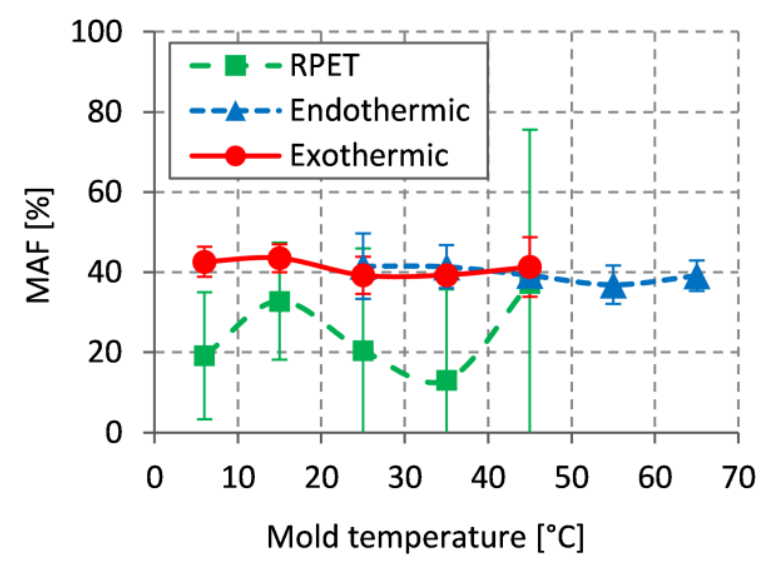

